Article

\title{
Antioxidant Activities and Caffeic Acid Content in New Zealand Asparagus (Asparagus officinalis) Roots Extracts
}

\author{
Abbey Symes ${ }^{1}$ (1) , Amin Shavandi ${ }^{1}$ (D), Hongxia Zhang ${ }^{1}$, Isam A. Mohamed Ahmed ${ }^{2}$ (D), \\ Fahad Y. Al-Juhaimi ${ }^{2}$ and Alaa El-Din Ahmed Bekhit 1,* \\ 1 Department of Food Science, University of Otago, Dunedin 9054, New Zealand; \\ abbeysymes77@gmail.com (A.S.); amin.shavandi@otago.ac.nz (A.S.); \\ hongxia.zhang@postgrad.otago.ac.nz (H.Z.) \\ 2 Department of Food Science and Nutrition, College of Food and Agricultural Sciences, King Saud University, \\ Riyadh 11451, Saudi Arabia; isamnawa@yahoo.com (I.A.M.A.); faljuhaimi@ksu.edu.sa (F.Y.A.-J.) \\ * Correspondence: aladin.bekhit@otago.ac.nz; Tel.: +64-3479-4994
}

Received: 4 March 2018; Accepted: 30 March 2018; Published: 4 April 2018

\begin{abstract}
Asparagus officinalis are perennial plants that require re-planting every 10-20 years. The roots are traditionally mulched in the soil or treated as waste. The $A$. officinalis roots (AR) contain valuable bioactive compounds that may have some health benefiting properties. The aim of this study was to investigate the total polyphenol and flavonoid contents (TPC and TFC, respectively) and antioxidant (2,2-diphenyl-1-picrylhydrazyl (DPPH), Oxygen Radical Absorbance Capacity (ORAC) and Ferric Reducing/Antioxidant Power (FRAP) assays) activities of New Zealand AR extract. The antioxidant activity decreased with a longer extraction time.
\end{abstract}

Keywords: asparagus roots; antioxidant activity; bioactive compounds

\section{Introduction}

Asparagus belongs to the Asparagaceae genus, which originated in the Eastern Mediterranean region and Asia. Asparagus is a versatile plant with a unique texture and flavour that has promoted its consumption worldwide. There are 22 different species of asparagus recorded in India [1]. Most of the research on the bioactive properties of asparagus extracts was carried out on extracts obtained from the shoots of Asparagus officinalis and the roots of A. racemosus [2,3]. Different parts of A. racemosus have been suggested to have health benefits such as improving the immune system and cancer prevention [4,5]. A. officinalis is mainly cultivated for the consumption of the shoot, but its roots have no value and very little research has been carried out on bioactives in the roots of this important plant.

A. officinalis can be harvested for up to 40 years or until their productivity and quality decline. The quality of asparagus declines over time due to diseases from microorganisms, such as Fusarium, Phytophthora, Stemphylium, Phomopsis asparagi, and Cercospora asparagi Sacc species, as well as the autotoxins that asparagus itself produces, which hinder the growth of new asparagus plants [6]. Therefore, the regeneration of the rootstock becomes necessary for productivity. Old asparagus roots are considered as a waste in many countries, including New Zealand, and are commonly left to rot in fields. However, asparagus waste, not including the roots, has been reported as a potential source of bioactive compounds such as saponins, polyphenols, and flavonoids [7]. These bioactive compounds could be extracted from the roots, hence utilising the roots in a manageable manner and offers the opportunity to add value to the production process. The roots also possess allopathic properties, which can prevent other asparagus plants from growing. Therefore, farmers could improve the re-growth of new asparagus by removing the allopathic potential of old roots, as well as increasing their income by 
selling the roots, allowing the recipients of the bioactive compounds to have access to a natural product with potential health benefits. Environmental factors such as temperature and exposure to UV and soil nutrients can affect the synthesis and the content of bioactives in plants. Therefore, the objective of this study was to determine the antioxidant activity of New Zealand A. officinalis root extracts obtained using methanol and ethanol as the most commonly used extraction solvents.

\section{Materials and Methods}

Methanol, ethanol, sodium carbonate, acetonitrile, trifluoroacetic acid, and sodium acetate were obtained from Fisher Scientific (Waltham, MA, USA). Gallic acid, sodium nitrite, rutin, 2,2-diphenyl-1 -picrylhydrazyl (DPPH), fluorescein sodium salt, 6-hydroxy-2,5,7,8-tetramethylchroman-2-carboxylic acid (Trolox), 2,4,6-tris(2-pyridyl)-s-triazine (TPTZ), caffeic acid, saponin, and ferrous sulphate were obtained from Sigma-Aldrich (St. Louis, MO, USA). Folin-Ciocalteu reagent and di-sodium phosphate decahydrate were purchased from Merck Millipore Corporation (Billerica, MA, USA); aluminium chloride from Loba Chemie (Mumbai, India); sodium hydroxide and glacial acetic acid from VWR International, (Radnor, PA, USA), sodium dihydrogen orthophosphate 1-hydrate and ferric chloride from BDH Chemicals LTD (Poole, UK); 2,2'-azobis-2-methyl-propanimidamide dichloride (AAPH) from the Cayman Chemical Company (Ann Arbor, MI, USA). All chemicals used were of analytical grade.

\subsection{Preparation of Asparagus Roots}

New Zealand green and purple AR roots were obtained from a commercial farm in Palmerston (New Zealand) $\left(40.3523^{\circ} \mathrm{S}, 175.6082^{\circ} \mathrm{E}\right)$ from plants that had been planted for 15 years. The $A$. officinalis roots (AR) were cleaned from soil and other contaminants were removed from the roots by thoroughly washing them with tap water and then rinsing them with deionized water [8]. Then the roots were dried using an oven (Contherm 2150, Contherm Scientific Limited, Upper Hut, New Zealand) at $60^{\circ} \mathrm{C}$ for $72 \mathrm{~h}$. The dried roots were then pulverized into a powder using a Jingangdikai JG100 grinder (Jingangdikai Co., Guandong, China) and sieved through a $40 \mathrm{~mm}$ mesh. The dried root powder samples were transferred into closed plastic containers and kept at $-20^{\circ} \mathrm{C}$ until further analysis.

\subsection{Extraction of Bioactive Compounds}

The effects of extraction solvent (water, methanol or ethanol), solvent concentration, number of extractions (reflect the number of extractions of the same sample) and extraction time on the yield and antioxidant activities of the extracts were investigated. A modified method of Fan et al. [9] was carried out for the extraction of bioactive compounds from the AR. The AR powder was extracted using deionized water, methanol or ethanol at different concentrations $(50 \%, 70 \%$, and $90 \%)$. The samples were extracted twice and all extractions were carried out with triplicate samples. For the first extraction, $10 \mathrm{~g}$ of the AR powder was combined with $200 \mathrm{~mL}$ of the extraction solvent in a flask. The samples were then wrapped in aluminium foil and placed into a shaking incubator (Ratek, Victoria, Australia) at $70{ }^{\circ} \mathrm{C}$ for $2 \mathrm{~h}$ shaking at a speed of $80 \mathrm{RPM}$. After $2 \mathrm{~h}$, the samples were centrifuged (J2-21 M/E Beckman, Brea, CA, USA) at 10,000 $\times g$ for $20 \mathrm{~min}$ and the supernatant was filtered using Whatman No 1 filter paper by vacuum. The methanol and ethanol in the extracted samples were removed using a Rotavapor ${ }^{\circledR}$ (Büchi, Chadderton, UK) at $40{ }^{\circ} \mathrm{C}$, and then the samples were frozen at $-80^{\circ} \mathrm{C}$ before being freeze-dried (Labconco, Kansas City, MO, USA). The pellets from the centrifuge and filter steps were subjected to a second extraction as described above. The samples from both extractions were kept separate and referred to in the following sections as "extraction order". The samples were frozen at $-80{ }^{\circ} \mathrm{C}$ and freeze-dried. This process was repeated using the same solvent: solid ratio, and extraction 
temperature using ethanol as the extraction solvent at a longer extraction time of $10 \mathrm{~h}$. The yield was calculated using the following equation:

$$
\text { Yield }(\%)=\frac{(\text { Weight of freeze }- \text { dried extract })}{\text { Weight of dried asparagus roots }} \times 100
$$

\subsection{Analysis of Asparagus Root Extracts}

The samples were analysed for their TPC (Total phenolic content), TFC (Total phenolic content) and antioxidant activities using solutions prepared fresh on the day of analysis $(1 \mathrm{mg} / \mathrm{mL}$ in $50 \%$ methanol), kept on ice and protected from light. All analyses were carried out in triplicate measurements.

\subsection{Total Phenolic Content}

To determine the TPC of the samples, the Folin-Ciocalteu colourimetric method was carried out using a plate reader (Biotek, Winooski, VT, USA) as described by Farasat et al. [10]. In a 96-well microplate, $20 \mu \mathrm{L}$ of the extract was added, followed by $100 \mu \mathrm{L}$ of Folin-Ciocalteu reagent (1:10) and $80 \mu \mathrm{L}$ of sodium carbonate $(7.5 \%)$. The plate was left in the dark at room temperature for $30 \mathrm{~min}$, and the absorbance was read at $600 \mathrm{~nm}$. Gallic acid was used to construct a standard curve $(0-0.15 \mathrm{mg} / \mathrm{mL})$, hence the polyphenol content of the samples was expressed as Gallic Acid Equivalents per gram of extract (mg GAE/g extract).

\subsection{Total Flavonoid Content}

The aluminium chloride colourimetric method of Herald et al. [11] was carried out using a plate reader to determine the TFC. In a 96-well microplate, $100 \mu \mathrm{L}$ of distilled water, $10 \mu \mathrm{L}$ of sodium nitrite $(50 \mathrm{~g} / \mathrm{L})$, and $25 \mu \mathrm{L}$ of the extract solution were added to each well. After $5 \mathrm{~min}$ of incubation in the dark at room temperature, $15 \mu \mathrm{L}$ of aluminium chloride $(100 \mathrm{~g} / \mathrm{L})$ was added and the mixture was left for a further $6 \mathrm{~min}$ in the dark at room temperature. Finally, $50 \mu \mathrm{L}$ of sodium hydroxide $(1 \mathrm{~mol} / \mathrm{L})$ and $50 \mu \mathrm{L}$ of distilled water were added to the wells. The absorbance of the mixture was measured at $510 \mathrm{~nm}$ and rutin was used to construct a standard curve $(1-0.05 \mathrm{mg} / \mathrm{mL})$, hence the flavonoid content of the samples was expressed as rutin equivalent per gram of extract (mg RE/g extract).

\subsection{Antioxidant Activity}

\subsubsection{Determination of DPPH Radical Scavenging Activity}

The DPPH assay was conducted using the method described by De-Ancos et al. [12] using a plate reader. A $10 \mu \mathrm{L}$ of the sample and $90 \mu \mathrm{L}$ of deionized water were added to each well of a 96-well microplate. Then, in dimmed light, $100 \mu \mathrm{L}$ of DPPH $(78 \mathrm{mg} / \mathrm{L})$ was added to each well. The plate was left in the dark at $25^{\circ} \mathrm{C}$ for $30 \mathrm{~min}$ before the absorbance was measured at $517 \mathrm{~nm}$. Gallic acid was used to construct a standard curve, and the DPPH scavenging activity was determined as DPPH inhibition (\%) from the equation:

$$
\text { DPPH Inhibition }=\frac{(1-\text { test sample })}{\text { blank sample absorbance }} \times 100
$$

\subsubsection{Determination of Oxygen Radical Absorbance Capacity (ORAC)}

The method of Huang et al. [13] was used to determine the ORAC. Phosphate buffer (75 mM, $\mathrm{pH}$ 7.4) was prepared and a stock solution of $1 \mathrm{mM}$ of fluorescein sodium salt was made using the buffer, wrapped in aluminium foil and kept at $4{ }^{\circ} \mathrm{C}$. This stock solution was diluted further to make a $10 \mathrm{nM}$ solution, which was used on the day of the assay. The AAPH was made by dissolving $0.0646 \mathrm{~g}$ in $1 \mathrm{~mL}$ of the phosphate buffer. The $10 \mathrm{nM}$ fluorescein and AAPH solutions were kept on ice in the 
dark until use and were made fresh daily. For the standard curve Trolox $(0-150 \mathrm{mM})$ was prepared in phosphate buffer and used to construct the standard curve.

A $25 \mu \mathrm{L}$ of the standard or sample and $150 \mu \mathrm{L}$ of the $10 \mathrm{nM}$ fluorescein were pipetted into a 96-well microplate in the dark. Then the plate was covered in parafilm and placed in the plate reader at $37^{\circ} \mathrm{C}$ for $30 \mathrm{~min}$. A $25 \mu \mathrm{L}$ of APPH was added, the plate was shaken for $20 \mathrm{~s}$, and the fluorescence was read at excitation at $485 \mathrm{~nm}$ and emission at $527 \mathrm{~nm}$, at 1-min intervals over $1.5 \mathrm{~h}$. The results were analysed by calculating the AUC, using the following equation:

$$
\mathrm{AUC}=1+\sum_{t_{0}=0 \min }^{t_{i}=90 \min } \frac{A_{i}}{A_{0}}
$$

where $A_{0}$ is the initial fluorescence reading at $t_{0}$ and $A_{i}$ is the reading at $t_{i}$ hence, the final ORAC results were the difference between the area under the curve the blank and the samples. The results were expressed as $\mathrm{mM}$ Trolox equivalents per gram of extract (mM TE/g extract).

\subsubsection{Ferric Reducing Ability Power (FRAP) Assay}

The method of Benzie and Strain [14] was used with some modifications as reported by Teh et al. [15] so that it could be applied to a plate reader in a 96-well microplate. A FRAP solution was made in acetate buffer ( $300 \mathrm{mM}, \mathrm{pH}$ 3.6) that contained $10 \mathrm{mM} \mathrm{TPTZ}, 20 \mathrm{mM} \mathrm{FeCl}_{3}$ and deionized water. The $10 \mathrm{mM}$ TPTZ was made up in $10 \mathrm{~mL}$ of $\mathrm{HCl}(40 \mathrm{nM})$ and placed in a water bath at $50{ }^{\circ} \mathrm{C}$ until the compound was dissolved. The $20 \mathrm{mM} \mathrm{FeCl}_{3}$ was made up in $10 \mathrm{~mL}$ of distilled water.

FRAP solution $100 \mathrm{~mL}$ of the acetate buffer $(300 \mathrm{mM}, \mathrm{pH} 3.6), 10 \mathrm{~mL}$ of TPTZ $(10 \mathrm{mM})$ and $10 \mathrm{~mL}$ of $\mathrm{FeCl}_{3}$ were combined and kept at $37^{\circ} \mathrm{C}$ until use. This solution was made fresh daily. For the standard curve, iron sulphate was used (0-1.5 mM). In a 96-well microplate, $10 \mu \mathrm{L}$ of the standard (iron sulphate) or sample was added, followed by $200 \mu \mathrm{L}$ of the FRAP solution. The plate was incubated at $37^{\circ} \mathrm{C}$ for $4 \mathrm{~min}$ inside the plate reader. The results were expressed as $\mathrm{mM}$ iron sulphate equivalents per gram of extract $\left(\mathrm{mM} \mathrm{FeSO}_{4} \mathrm{E} / \mathrm{g}\right.$ extract).

\subsection{HPLC Analysis}

Reverse phase HPLC [9] was used to separate and quantify the bioactive compounds extracted from the different extraction methods. All of the samples were filtered into $2 \mathrm{~mL}$ amber vials using a $0.45 \mu \mathrm{m}$ nylon filter (Phenomenex, Torrance, CA, USA). The amber vials were then placed into the auto-sampler chamber, which was kept at $4{ }^{\circ} \mathrm{C}$ during the analysis. The HPLC used was an Agilent 1200 (Agilent Technologies, Santa Clara, CA, USA), with autosampler and Diode Array Detector (DAD). The column used was a Luna C18 $(5 \mu \mathrm{m}, 250 \times 4.6 \mathrm{~mm}$, Phenomenex, Torrance, CA, USA), with a $10 \mu \mathrm{m}$ $4 \times 3 \mathrm{~mm} \mathrm{C18}$ guard column (Phenomenex, Torrance, CA, USA). The column was maintained at $25^{\circ} \mathrm{C}$. The mobile phase consisted of Milli-Q water (A) and acetonitrile containing $0.02 \% v / v$ of trifluoroacetic acid (TFA) (B). Preliminary work using several standards (quercetin, rutin, gallic acid, ferulic acid, and caffeic acid) showed that the main compound in AR is caffeic acid. The caffeic acid content in the obtained extracts of the analytes was identified and quantified by comparing the retention time of the peak with a reference standard eluted under the same conditions.

\subsection{Statistical Analysis}

The statistical analysis was carried out using Minitab 16 Statistical Software (State College, PA, USA) using the general linear model (GLM) protocol. The investigated parameters were the TPC, TFC, caffeic acid and DPPH, ORAC and FRAP activities of AR extracts. For the solvent extraction method, a multivariate analysis of variance (ANOVA) was carried out to examine the effects of extraction solvent (methanol, ethanol, and water), solvent concentration $(50 \%, 70 \%$, and $90 \%)$, extraction order (1st and 2nd extraction) and their interactions on the measured parameters. The results for 2-h and 10-h extraction times using ethanol were analysed separately. Tukey's honestly significant difference 
(HSD) post hoc test was used for multi comparison tests. A Pearson's correlation was also carried out to determine the correlations among the measured parameters.

\section{Results and Discussion}

In agreement with the literature, the conditions required for the optimal conventional extraction method of bioactive compounds from plant materials depended greatly on the extraction order and time, extraction solvent and concentration [16].

\subsection{Extraction Time and Order on the Yield}

There was a significant effect for the extraction order $(p<0.05)$ in both 2-h and 10-h extractions, where the 1st extraction had a significantly higher yield compared to the 2nd extraction (Table 1). A careful evaluation of the economics of the process needs to be considered as to whether it would be worthwhile for a 2nd extraction to be carried out (i.e., the yield and activity would have to provide enough incentive for the extra processing time and cost). The yield from 10-h 1st extraction was significantly higher than the 2-h comparable extraction $(p<0.01$, data not shown). The obtained extracts reflected a mix of several cellular biomaterials, including carbohydrates. Therefore, it was important to evaluate the bioactivity of the extract rather than limiting the evaluation on crude extract, since the maximum amount of bioactive compounds extracted by the solvent may have varied due to differences in the compounds' affinity toward the various extraction solvents.

Table 1. The yield of extracts (Mean \pm SEM) obtained using solvent extraction methods. ${ }^{a, b}$ Within each extraction and ${ }^{x-z}$ within each extraction time, values that do not share the same letter are significantly different $(p<0.05)$.

\begin{tabular}{cccc}
\hline Extraction Time & Extraction Solvent & Extraction Order & Average Yield (\%) \\
\hline $2-\mathrm{h}$ & $50 \%$ Methanol & 1 & $42.4 \pm 1.8^{\mathrm{a}}$ \\
$70 \%$ Methanol & 1 & $42.1 \pm 1.8^{\mathrm{a}}$ \\
$90 \%$ Methanol & 1 & $41.8 \pm 1.8^{\mathrm{a}}$ \\
$50 \%$ Ethanol & 1 & $44.0 \pm 1.8^{\mathrm{a}}$ \\
$70 \%$ Ethanol & 1 & $44.3 \pm 1.8^{\mathrm{a}}$ \\
$90 \%$ Ethanol & 1 & $36.4 \pm 1.8^{\mathrm{a}}$ \\
Water & 1 & $38.4 \pm 1.8^{\mathrm{a}}$ \\
$50 \%$ Methanol & 2 & $3.2 \pm 1.8^{\mathrm{b}}$ \\
$70 \%$ Methanol & 2 & $3.4 \pm 1.8^{\mathrm{b}}$ \\
$90 \%$ Methanol & 2 & $3.0 \pm 1.8^{\mathrm{b}}$ \\
$50 \%$ Ethanol & 2 & $3.6 \pm 1.8^{\mathrm{b}}$ \\
$70 \%$ Ethanol & 2 & $5.1 \pm 1.8^{\mathrm{b}}$ \\
$90 \%$ Ethanol & 2 & $7.0 \pm 1.8^{\mathrm{b}}$ \\
Water & 2 & $4.2 \pm 1.8^{\mathrm{b}}$ \\
\hline $10-\mathrm{h}$ & $50 \%$ Ethanol & 1 & $53.6 \pm 3.4^{\mathrm{x}}$ \\
& $70 \%$ Ethanol & 1 & $60.1 \pm 3.4^{\mathrm{x}}$ \\
$90 \%$ Ethanol & 1 & $29.8 \pm 3.4^{\mathrm{y}}$ \\
$50 \%$ Ethanol & 2 & $12.8 \pm 3.4^{\mathrm{z}}$ \\
& $70 \%$ Ethanol & 2 & $6.4 \pm 3.4^{\mathrm{z}}$ \\
& $90 \%$ Ethanol & 2 & $7.2 \pm 3.4^{\mathrm{z}}$ \\
\hline
\end{tabular}

\subsection{Effect of Extraction Solvent on TPC, TFC, and Antioxidant Activity}

There were significant effects for the extraction solvents during 2-h extraction time on the TPC, TFC and FRAP activity $(p<0.001)$ but not the DPPH scavenging (DPPH) and ORAC activities (Tables 2 and 3). There were no differences between ethanol and methanol for TFC and FRAP activity. Given that methanol led to a small increase (about 5-7\%) in TPC and with the known toxicity of methanol, it was decided that ethanol was the best extraction solvent as it would be more acceptable as an extraction solvent for health reasons [17-19]. The best extraction solvent to extract the 
maximum amount of bioactive compounds is dependent on the type of plant matrix in question [16]. Different amounts of antioxidant compounds were extracted by methanol, ethanol and water from plants materials, which was depended on the polarity, density and $\mathrm{pH}$ [16]. Hence, different antioxidant compounds have varying optimal extraction conditions. Although polyphenols and flavonoids are polar compounds, they express maximum extraction potential when are extracted from a solvent containing a combination of polar and non-polar substances [20]. Therefore, it was possible that different compounds were extracted in the different extraction solvents. The best extraction solvent determined in this research is in agreement with the literature on the extraction of bioactives from asparagus, as ethanol was found to be the most popular extraction solvent $[2,3,9,21,22]$. Methanol was found to be the optimum extraction solvent when it was used as pure methanol in a Soxhlet system [23,24]. During preliminary trials, a Soxhlet extraction method was carried out; however, it was found to be time-consuming and required a high amount of solvent, which resulted in high cost and a lot of organic waste to manage. Ideally, the best method needed for this type of research should be simple and easy to carry out, so that the commercialization pathway is affordable and commercially viable. Therefore, the ethanol extraction process was chosen for further investigations.

The extraction was carried out using two extractions times; $2-\mathrm{h}$ and $10-\mathrm{h}$. The 2-h and 10-h extraction times resulted in different $(p<0.05)$ antioxidant activities (Figure 1). For the TPC, ORAC, and FRAP, a 2-h extraction had higher activities compared to 10-h extraction. For the TFC and DPPH activity, the opposite was true. Fan et al. [9] investigated a range of extraction times up to $2.5 \mathrm{~h}$ and concluded that an extraction time of 2-h was sufficient to extract the maximum amount of antioxidant compounds from asparagus residue. From time 0 to $2.5 \mathrm{~h}$, it was found that the amount of antioxidants extracted increased until it reached a constant value at $2 \mathrm{~h}$ and then decreased slightly with the increase in extraction time. This was not found in this research, as the amount of antioxidants extracted from the 10-h extraction was not less than the 2-h extraction. Solana, Boschiero, Dall'Acqua, and Bertucco [24] determined that in whole $A$. officinalis and found a longer extraction time $(4 \mathrm{~h})$ allowed more phenolic acids to be extracted.

In the present study, a long extraction time resulted in a lower amount of total polyphenols (Figure 1a). This was in agreement with Shi et al. [25] findings in grape seeds. Oxidation of the polyphenols during the long processing time may have resulted in polymerised insoluble compounds and reduced total polyphenols [25].

There was a significant effect for the extraction order $(p<0.05)$ in both 2-h and 10-h extractions, where the 1st extraction had a significantly higher yield compared to the 2 nd extraction. The yield from the 10-h 1st extraction was significantly higher $(p<0.05)$ than the 2-h comparable extraction. The use of a 2nd extraction step appears to be important as it led to up to $20 \%$ recovery of yield, such as with $90 \%$ ethanol (Table 1). Other materials in the literature determined that a two-step extraction process resulted in the maximum amount of antioxidant compounds [25-27].

In the 2-h extraction, TPC per gram extract from the 1st and 2nd extractions were not different and a similar trend was found with TFC. However, ORAC and FRAP activities were affected $(p<0.05)$ by the extraction order (Figure 1). For the 10-h extraction, higher TPC and TFC $(p<0.05)$ were found in extracts from the 2nd extraction compared to the 1st extraction (Figure 1). Nawaz, Shi, Mittal, and Kakuda [27] investigated the optimal number of extractions to recover the maximum amount of polyphenols from grape seeds. The authors found that two extractions were ideal for that purpose. They found that the diffusion rate of the solute from the grape seeds decreased with increasing number of extractions. The extraction of bioactive is regulated by the diffusion of the extraction solvent into the matrix particles, where the driving force is the difference in pressure; and also by the diffusion of the antioxidant compounds from the matrix into the extraction solvent, where the driving force is the concentration difference [27]. As more antioxidant compounds were removed in the 1st extraction step, the concentration difference would have decreased, resulting in less compounds being extracted. Additional antioxidant compounds were extracted in the 2nd extraction due to disruption of the matrix during the 1st extraction, allowing the solvent in the 2nd extraction to diffuse more easily and extract 
more bioactives [28]. Hence, several researchers found a 3rd extraction is not justified (Nawaz, Shi, Mittal and Kakuda [27]; Cacace and Mazza [29]. In terms of yield, a 2nd extraction step would require economical evaluation in terms of benefit-cost relationship.

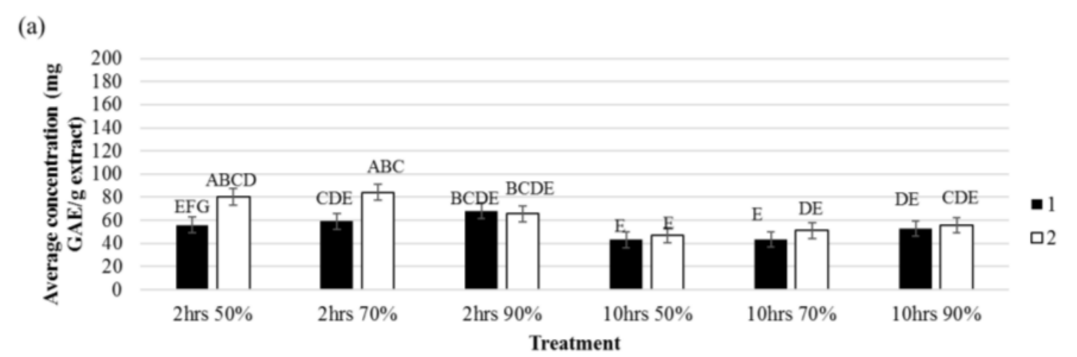

(b)

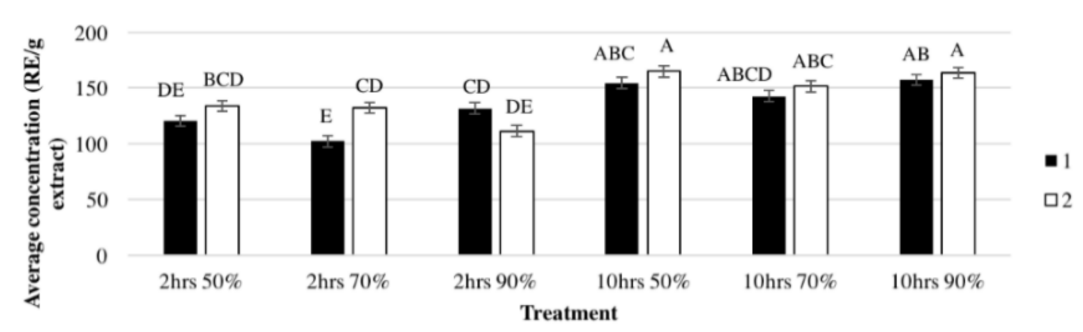

(c)

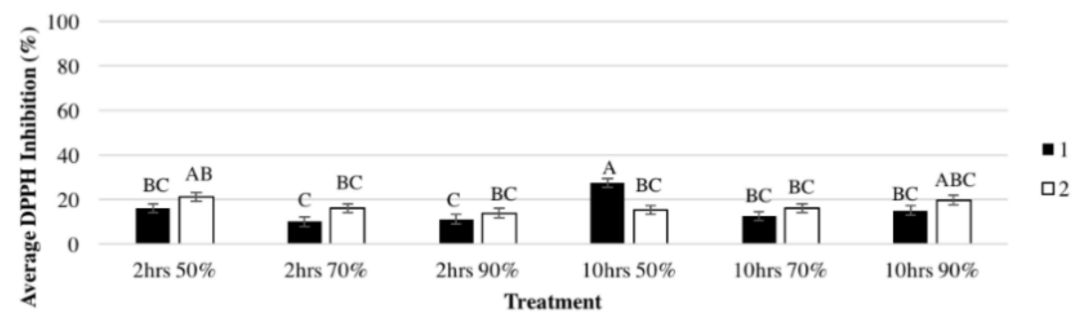

(d)

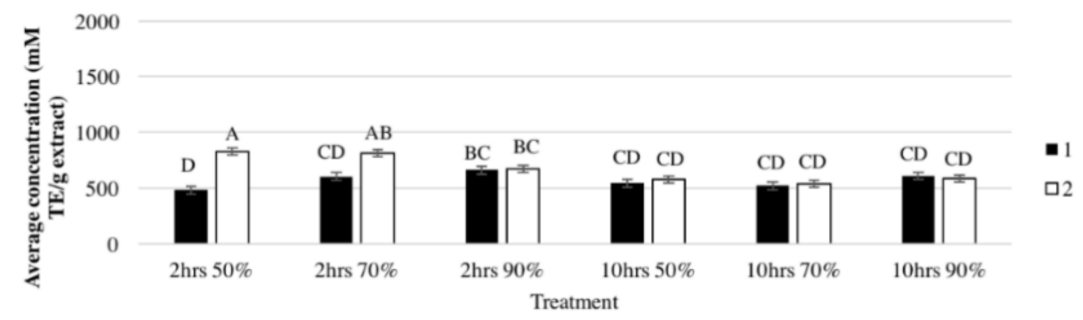

(e)

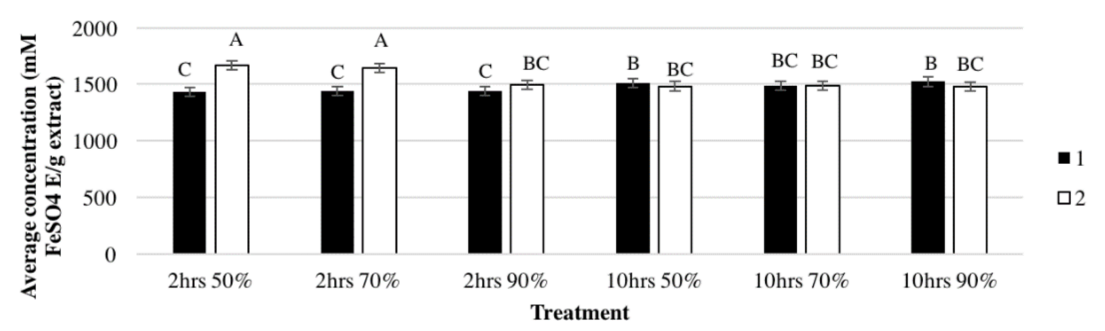

Figure 1. The effect of ethanol concentration, extraction order and extraction time on total phenolic content (a); total flavonoid content (b); 2,2-diphenyl-1-picrylhydrazyl (DPPH) scavenging activity (c); Oxygen Radical Absorbance Capacity (ORAC) activity (d); and Ferric Reducing/ Antioxidant Power (FRAP) activity (e) of the extract obtained from asparagus root powder after 2 and 10-h extraction time. Bars that do not share the same letter are significantly different $(p<0.05)$. 
Table 2. Summary of antioxidant activities of asparagus root extract obtained from 2-h extraction. ${ }^{\text {a-h }}$ Values that do not share the same letter are significantly different $(p<0.05)$.

\begin{tabular}{|c|c|c|c|c|c|c|c|c|c|c|c|c|}
\hline \multirow{3}{*}{ Solvent } & \multirow{2}{*}{\multicolumn{2}{|c|}{$\begin{array}{c}\begin{array}{c}\text { Total Polyphenols (mg } \\
\text { GAE/g Extract) }\end{array} \\
\text { Order }\end{array}$}} & \multirow{2}{*}{\multicolumn{2}{|c|}{$\begin{array}{c}\begin{array}{c}\text { Total Flavonoids (mg } \\
\text { RE/g Extract) }\end{array} \\
\text { Order }\end{array}$}} & \multirow{2}{*}{\multicolumn{2}{|c|}{$\begin{array}{c}\text { DPPH Inhibition \% } \\
\text { Order }\end{array}$}} & \multirow{2}{*}{\multicolumn{2}{|c|}{$\begin{array}{c}\begin{array}{c}\text { ORAC Antioxidant Activity } \\
\text { (mM TE/g Extract) }\end{array} \\
\text { Order }\end{array}$}} & \multirow{2}{*}{\multicolumn{2}{|c|}{$\begin{array}{c}\begin{array}{c}\text { FRAP Antioxidant Activity } \\
\text { (mM FeSO } \\
\text { (m/g Extract) }\end{array} \\
\text { Order }\end{array}$}} & \multirow{2}{*}{\multicolumn{2}{|c|}{$\begin{array}{c}\begin{array}{c}\text { Caffeic Acid }(\mathrm{mg} / \mathrm{g} \\
\text { Extract) }\end{array} \\
\text { Order }\end{array}$}} \\
\hline & & & & & & & & & & & & \\
\hline & 1 & 2 & 1 & 2 & 1 & 2 & 1 & 2 & 1 & 2 & 1 & 2 \\
\hline Methanol 50\% & $61.5^{\text {efg }}$ & $78.8^{\text {efg }}$ & $128.6^{\mathrm{d}}$ & $126.6^{\mathrm{d}}$ & $23.6^{d}$ & 40.8 abcd & $557.6 \mathrm{de}$ & 596.9 ade & $1445.0^{\mathrm{d}}$ & $1572.5^{b c}$ & $2.5^{\mathrm{ab}}$ & $2.7 \mathrm{ab}$ \\
\hline Methanol 70\% & 67.9 efg & $84.7^{\text {defg }}$ & 122.5 de & $127.7^{\mathrm{d}}$ & $47.0^{\mathrm{a}}$ & $42.3^{\mathrm{abcd}}$ & $776.1 \mathrm{abc}$ & $676.5^{\mathrm{abcd}}$ & $1439.8^{\mathrm{d}}$ & $1632.1 \mathrm{ab}$ & $2.2^{\mathrm{ab}}$ & $2.7^{\mathrm{ab}}$ \\
\hline Methanol 90\% & 64.9 efg & 91.4 def & $118.0 \mathrm{de}$ & $123.3^{\text {de }}$ & $39.9 \mathrm{abcd}$ & $29.1 \mathrm{abcd}$ & $591.1 \mathrm{de}$ & $699.3 \mathrm{abcd}$ & $1451.0^{\mathrm{d}}$ & $1638.4^{\mathrm{ab}}$ & $2.6^{\mathrm{ab}}$ & $2.5^{\mathrm{ab}}$ \\
\hline Ethanol 50\% & $56.1^{\mathrm{h}}$ & $80.2^{\text {efg }}$ & $120.4^{\text {de }}$ & $134.0^{\mathrm{d}}$ & $41.8 \mathrm{abcd}$ & $38.3^{\mathrm{abcd}}$ & $481.1^{\mathrm{e}}$ & $829.5^{\mathrm{a}}$ & $1435.1^{\mathrm{d}}$ & $1668.6^{\mathrm{a}}$ & $1.7^{\mathrm{b}}$ & $2.8^{\mathrm{a}}$ \\
\hline Ethanol 70\% & 59.1 efg & $84.2^{\text {defg }}$ & $102.1^{\mathrm{e}}$ & $132.3^{\mathrm{d}}$ & $27.1^{\mathrm{cd}}$ & $41.2^{\mathrm{abcd}}$ & $604.3^{\mathrm{de}}$ & $811.8 \mathrm{ab}$ & $1438.3^{d}$ & $1646.3^{\mathrm{a}}$ & $1.7^{\mathrm{b}}$ & $3.0^{\mathrm{a}}$ \\
\hline Ethanol 90\% & $68.4^{\text {efg }}$ & 65.7 efg & 131.9 de & $119.4^{\mathrm{d}}$ & $26.1^{\mathrm{abcd}}$ & $32.1 \mathrm{abcd}$ & $661.2^{\text {abcd }}$ & $670.7 \mathrm{abcd}$ & $1439.8^{\mathrm{d}}$ & $1494.0^{\mathrm{d}}$ & $3.0^{\mathrm{a}}$ & $2.3^{\mathrm{ab}}$ \\
\hline Water & $52.0 \mathrm{~g}$ & $63.7^{\text {defg }}$ & $109.3^{\text {de }}$ & 110.9 de & $41.5^{\mathrm{abcd}}$ & $23.8^{\mathrm{d}}$ & 593.2 de & $655.6^{\mathrm{abcd}}$ & $1422.4^{\mathrm{d}}$ & $1487.6^{\mathrm{d}}$ & $2.1^{\mathrm{ab}}$ & $2.1^{\mathrm{ab}}$ \\
\hline
\end{tabular}

Gallic Acid Equivalents (GAE); Rutin Equivalent (RE); 2,2-diphenyl-1-picrylhydrazyl (DPPH); Trolox Equivalents (TE); Oxygen Radical Absorbance Capacity (ORAC); Ferric Reducing/Antioxidant Power (FRAP).

Table 3. $p$-Values found for the effects of conventional extraction parameters on the total polyphenol content, total flavonoid content, and antioxidant activity (DPPH, ORAC and FRAP) of extracts obtained from AR $(p<0.05$ indicates significance).

\begin{tabular}{|c|c|c|c|c|c|c|}
\hline Time & Factor & Total Polyphenols & Total Flavonoids & DPPH Inhibition \% & ORAC & FRAP \\
\hline \multirow{7}{*}{$2 \mathrm{~h}$} & Extraction Solvent & 0.000 & 0.000 & 0.270 & 0.127 & 0.000 \\
\hline & Concentration & 0.161 & 0.200 & 0.012 & 0.131 & 0.218 \\
\hline & Extraction Order & 0.000 & 0.000 & 0.100 & 0.000 & 0.000 \\
\hline & Extraction Solvent Concentration & 0.600 & 0.011 & 0.002 & 0.005 & 0.000 \\
\hline & Extraction Solvent $\times$ Extraction Order & 0.641 & 0.095 & 0.001 & 0.000 & 0.000 \\
\hline & Concentration $\times$ Extraction Order & 0.154 & 0.053 & 0.339 & 0.021 & 0.099 \\
\hline & Extraction Solvent $\times$ Concentration $\times$ Extraction Order & 0.071 & 0.039 & 0.002 & 0.000 & 0.000 \\
\hline \multirow{3}{*}{$10 \mathrm{~h}$} & Concentration & 0.000 & 0.000 & 0.000 & 0.040 & 0.662 \\
\hline & Extraction Order & 0.000 & 0.000 & 0.298 & 0.613 & 0.101 \\
\hline & Concentration $\times$ Extraction Order & 0.001 & 0.163 & 0.000 & 0.526 & 0.413 \\
\hline \multirow{7}{*}{ Comparing $2 \mathrm{~h}$ and $10 \mathrm{~h}$} & Extraction Time & 0.000 & 0.000 & 0.015 & 0.000 & 0.002 \\
\hline & Concentration & 0.279 & 0.000 & 0.000 & 0.610 & 0.000 \\
\hline & Extraction Order & 0.000 & 0.000 & 0.160 & 0.000 & 0.000 \\
\hline & Extraction Time $\times$ Concentration & 0.060 & 0.499 & 0.451 & 0.059 & 0.000 \\
\hline & Extraction Time $\times$ Extraction Order & 0.005 & 0.000 & 0.014 & 0.000 & 0.000 \\
\hline & Concentration $\times$ Extraction Order & 0.336 & 0.004 & 0.010 & 0.000 & 0.000 \\
\hline & Extraction Time $\times$ Concentration $\times$ Extraction Order & 0.489 & 0.073 & 0.004 & 0.013 & 0.000 \\
\hline
\end{tabular}




\subsection{Effect of Extraction Time and Order on the Antioxidant Compounds}

The optimal condition to extract TPC involved a 2-h extraction and the use of $70 \%$ ethanol. In all cases, the 2nd extraction had slightly more, but insignificant TPC compared to the 1st extraction, except for 2-h 50\% ethanol (Figure 1a). For TFC, the 10-h extraction had more TFC compared with the 2-h extraction. The optimal conditions for TFC extraction were 10-h extraction using 50\% ethanol. Similar to the TPC, the 2nd extraction had slightly more, but insignificant TFC compared to the 1st extraction, with the exception of $2-\mathrm{h} 70 \%$ ethanol treatment.

The optimal conditions for the extraction of DPPH inhibition activity were using a 10-h extraction with $50 \%$ ethanol. Under these conditions, the extract from the 1st extraction significantly $(p<0.05)$ had more antioxidant activity compared to the 2 nd extraction. The optimal conditions for the extraction of ORAC antioxidant activity were 2 -h extraction using $70 \%$ ethanol, which had significantly $(p<0.05)$ higher ORAC activity compared to the 10-h extraction. Even though the 2-h and 50\% ethanol had the highest $(p<0.05)$ ORAC antioxidant activity in the 2nd extraction, the 2-h and 70\% ethanol treatment resulted in a combined higher ORAC activity.

The 2-h 50\% and 70\% ethanol treatments had significantly $(p<0.05)$ higher FRAP antioxidant activity compared to the other treatments. The optimal conditions for extracts for that activity were 2-h at 50\% ethanol. The 2nd extraction had more FRAP antioxidant activity compared to the 1st extraction in most cases (Figure 1e). This could be due to the matrix of the AR, as the 1st extraction would have disrupted the matrix, allowing the 2nd extraction to easily remove more antioxidants [27]. Furthermore, the removal of carbohydrates and other soluble compounds during the first extraction can help more specific extraction of antioxidants. To determine the optimal conditions to extract antioxidant compounds from AR, the extraction yields were calculated and are shown in Table 1 . There were no effects $(p>0.05)$ for the solvent or the solvent concentration on the yield of AR extracts (Table 1 ).

\subsection{Effect of Extraction Order and Solvent Type on Antioxidant Activity}

The interaction between extraction order and extraction solvent investigated for the 2-h extraction, as the 10-h extraction only examined the use of one solvent "ethanol". The extraction order and extraction solvent and their interaction had significant $(p<0.05)$ effects on the antioxidant activities of the extracts, which was dependent on the antioxidant assay used (Tables 2 and 3). The 1st extraction did not have a significant effect $(p>0.05)$ on DPPH inhibition activity compared to the 2nd extraction for all the solvents used. For the ORAC activity, only the $50 \%$ and $70 \% 2$ nd extraction of ethanol were significantly higher $(p<0.05)$ than the other extractions. Ethanol $90 \%$ and water 1 st extracts had significantly $(p<0.05)$ lower FRAP activity than their 2 nd counterpart extracts. The 2nd methanol $(50 \%$, $70 \%$, and $90 \%)$ and ethanol ( $50 \%$ and $70 \%)$ extracts had significantly $(p<0.05)$ higher FRAP activity found compared to water and ethanol $90 \%$ extracts. In general, methanol and ethanol extracts were similar in their antioxidant activity, while water extracts were significantly $(p<0.05)$ lower in most cases.

\subsection{Effect of Solvent Concentration}

Methanol and ethanol at different concentrations extracted the same amounts of TFC that were not different from water (Table 2). It is worth mentioning that the differences between ethanol and methanol in terms of TFC were less than $5-6 \%$, which economically may not be attractive to justify the use of a toxic chemical such as methanol. Methanol 70\% extract had the highest DPPH radical scavenging and ORAC activity (Figure 1 and Table 2). The FRAP activity of water and 90\% ethanol extracts were lower than the other treatment with the exception of $50 \%$ methanol extract (Figure 1). Generally, 70\% methanol and 50\% ethanol were good extraction solvents for antioxidants of AR, and water was the least effective extraction solvent. In the 10-h extraction method, only ethanol was used since generally little differences were observed between ethanol and methanol in 2-h extraction. The optimal solvent concentration for the extraction of antioxidant compounds from plants depends on the matrix of the plant and the properties of the antioxidant compounds [16]. Optimal ethanol 
concentration used for the extraction of bioactives from different asparagus types and parts ranged from $50 \%$ to $80 \%$ [2,3,9,21,22], which is in agreement with the findings in this study. This wide range of concentrations could be due to the polarity of the antioxidant compounds, and the affinity they have towards the extraction solvent [16]. Different solvent concentrations may be able to diffuse in the AR structure and extract different types and amounts of antioxidant compounds. Shi, Yu, Pohorly, Young, Bryan, and $\mathrm{Wu}$ [25] and Fan, Yuan, Wang, Gao, and Huang [9] reported that a concentration of $50 \%$ ethanol was optimal as it allowed the maximum amount of the water-soluble polyphenols to be extracted. Furthermore, 50\% ethanol has been known to be effective at extracting flavonoids [30], which is in accordance with the findings of this study.

\subsection{Effect of Extraction Order and Solvent Concentration on the Antioxidant Activity}

Only FRAP activity in 2-h extracts was significantly $(p<0.05)$ affected by the extraction order and the 2nd extraction had higher FRAP activity compared to the 1st extraction in all the solvents. In the 10-h extraction, TPC and DPPH activity were affected by the extraction order and solvent concentration $(p<0.05)$. Extracts obtained from the $90 \%$ solvent concentration significantly had higher TPC compared to $50 \%$ and $70 \%$ (Figure 1). There was an effect for the extraction order on TPC which was observed in $70 \%$ solvent concentration only. For the DPPH, 50\% ethanol the first extraction had the highest DPPH scavenging activity (Figure 1). This could have been due to the antioxidants responsible for the inhibition of DPPH being more favourable to be extracted by $50 \%$ ethanol due to the polarity [16]. The concentration did not greatly influence the extraction of antioxidant compounds, apart from DPPH. This is in agreement with the findings of Diankov et al. [31] who found a negligible concentration effect when extracting antioxidant compounds in lemon peels.

\subsection{Pearson Correlations for the Measured Activities in AR Extract}

Pearson correlations analysis was carried out on the 2-h extraction and the 10-h extraction to examine the influence of extraction time on these relationships (Table 4). In the 2-h extraction, there were many positive correlations $(p<0.05)$. The DPPH assay and flavonoids had a positive correlation. This meant that the TFC were affecting DPPH inhibition activity. The FRAP and ORAC assays both had positive correlations to polyphenols and flavonoids, therefore the polyphenols and flavonoids contributed towards the FRAP and ORAC antioxidant activities. The FRAP and ORAC assays also had a positive correlation with each other. This meant that these two methods may have targeted the same type of antioxidant. The positive correlation between antioxidants was in agreement with previous findings for basil leaves [16] and spinach [32].

Table 4. Pearson's Overall Correlation between the Antioxidant Assays in the 2-h Extraction $(p<0.05$ indicates significance).

\begin{tabular}{|c|c|c|c|c|c|c|}
\hline Extraction Time & Antioxic & ant Assay & Polyphenols & Flavonoids & DPPH & ORAC \\
\hline \multirow{4}{*}{ 2-h } & Flavonoids & $\begin{array}{c}\text { Pearson's coefficient } \\
p \text {-value }\end{array}$ & $\begin{array}{l}0.322 \\
0.000\end{array}$ & & & \\
\hline & DPPH Inhibition \% & $\begin{array}{c}\text { Pearson's coefficient } \\
p \text {-value }\end{array}$ & $\begin{array}{l}0.110 \\
0.228\end{array}$ & $\begin{array}{l}0.269 \\
0.003\end{array}$ & & \\
\hline & ORAC & $\begin{array}{l}\text { Pearson's coefficient } \\
p \text {-value }\end{array}$ & $\begin{array}{l}0.201 \\
0.025\end{array}$ & $\begin{array}{l}0.199 \\
0.028\end{array}$ & $\begin{array}{l}0.162 \\
0.076\end{array}$ & \\
\hline & FRAP & $\begin{array}{l}\text { Pearson's coefficient } \\
\quad p \text {-value }\end{array}$ & $\begin{array}{l}0.455 \\
0.000\end{array}$ & $\begin{array}{l}0.338 \\
0.000\end{array}$ & $\begin{array}{l}0.084 \\
0.353\end{array}$ & $\begin{array}{l}0.450 \\
0.000\end{array}$ \\
\hline \multirow{4}{*}{ 10-h } & Flavonoids & $\begin{array}{c}\text { Pearson's coefficient } \\
p \text {-value }\end{array}$ & $\begin{array}{l}0.433 \\
0.001\end{array}$ & & & \\
\hline & DPPH Inhibition \% & $\begin{array}{c}\text { Pearson's coefficient } \\
p \text {-value }\end{array}$ & $\begin{array}{l}-0.165 \\
0.232\end{array}$ & $\begin{array}{l}-0.110 \\
0.428\end{array}$ & & \\
\hline & ORAC & $\begin{array}{l}\text { Pearson's coefficient } \\
p \text {-value }\end{array}$ & $\begin{array}{l}0.171 \\
0.217\end{array}$ & $\begin{array}{l}0.280 \\
0.041\end{array}$ & $\begin{array}{c}-0.161 \\
0.244\end{array}$ & \\
\hline & FRAP & $\begin{array}{c}\text { Pearson's coefficient } \\
p \text {-value }\end{array}$ & $\begin{array}{l}0.003 \\
0.982\end{array}$ & $\begin{array}{l}0.109 \\
0.432\end{array}$ & $\begin{array}{l}-0.007 \\
0.962\end{array}$ & $\begin{array}{l}-0.075 \\
0.587\end{array}$ \\
\hline
\end{tabular}




\subsection{Analysis of AR Extract Using HPLC}

Caffeic acid is a hydrocinnamic acid, and it contributes towards the autotoxicity in A. officinalis roots [33]. The major phenolic peak detected in A. officinalis roots is controversial with rutin [34] or caffeic acid $[33,35]$ being alternatively reported as the highest phenolic compound in the roots of A. officinalis L. Although literature reported the presence of rutin in A. officinalis this was not reflected in the results of this study, as rutin was not found. This could have been due to the preparation conditions of A. officinalis AR samples, as Makris and Rossiter [36] found rutin degraded when A. officinalis spears were chopped. As shown in Table 2, after 2-h extraction the amount of caffeic acid was not affected by the solvent type $(p>0.05)$. Ethanol concentration and extraction order affected the caffeic acid content (Table 2), where $90 \%$ ethanol extract had higher caffeic acid content than the $50 \%$ and $70 \%$ ethanol extracts in the 1st extraction. Similarly, using $90 \%$ ethanol, 2.4 (mg/g extract) of caffeic acid was obtained after $10 \mathrm{~h}$ that was significantly higher than the $1.5 \mathrm{and} 1.3 \mathrm{mg} / \mathrm{g}$ extract obtained with $50 \%$ and $70 \%$ ethanol, respectively. Studies have shown that caffeic acid and its derivatives exhibit significant biological activities such as antioxidants to control lipid peroxidation [37] and have a potential therapeutic effect in treating neurodegenerative diseases [38].

\section{Conclusions}

The antioxidant activities of green asparagus root were determined using conventional hydro-alcohol extraction methods. It was concluded that one extraction was sufficient to extract the majority of antioxidant compounds as a 2nd extraction had a significantly lower yield and so would not have been worthwhile, in respect to the time and extraction solvent required. The optimal conditions were found to be using 50\% ethanol for 2-h, with a yield of 44\%. The 2-h extraction time allowed more TPC, ORAC, and FRAP activities to be obtained. Although more flavonoids were found in the 10-h extraction, they did not appear to contribute more towards these antioxidant activities. Rutin was not found in New Zealand A. officinalis roots and caffeic acid was found to be the dominant phenolic in AR extracts. The extraction method developed in this study was simple and easy to carry out. Therefore, this method would enable the use of asparagus roots as a valuable-by product and hence prevent them from being a waste.

Acknowledgments: The authors would like to thank Rod Philip (Palmerston asparagus Co.) for the kind donation of the samples. Also, the authors extend their appreciation to the International Scientific Partnership Program ISPP at King Saud University for funding this research work through ISPP\# 0073).

Author Contributions: Abbey Symes and Alaa El-Din Ahmed Bekhit conceived and designed the experiments; Abbey Symes and Hongxia Zhang performed the experiments; Alaa El-Din Ahmed Bekhit and Isam A. Mohamed Ahmed analysed the data; Amin Shavandi contributed reagents and materials; Alaa El-Din Ahmed Bekhit, Amin Shavandi and Fahad Y. Al-Juhaimi wrote the paper.

Conflicts of Interest: The authors declare no conflict of interest.

\section{References}

1. Kamat, J.P.; Boloor, K.K.; Devasagayam, T.P.; Venkatachalam, S. Antioxidant properties of Asparagus racemosus against damage induced by $\gamma$-radiation in rat liver mitochondria. J. Ethnopharmacol. 2000, 71, 425-435. [CrossRef]

2. Fuentes-Alventosa, J.M.; Jaramillo-Carmona, S.; Rodríguez-Gutiérrez, G.; Rodríguez-Arcos, R.; Fernández-Bolaños, J.; Guillén-Bejarano, R.; Espejo-Calvo, J.; Jiménez-Araujo, A. Effect of the extraction method on phytochemical composition and antioxidant activity of high dietary fibre powders obtained from asparagus by-products. Food Chem. 2009, 116, 484-490. [CrossRef]

3. Hossain, M.I.; Sharmin, F.A.; Akhter, S.; Bhuiyan, M.A.; Shahriar, M. Investigation of cytotoxicity and in-vitro antioxidant activity of Asparagus racemosus root extract. ICPJ 2012, 1, 250-257. [CrossRef]

4. Agrawal, A.; Sharma, M.; Rai, S.K.; Singh, B.; Tiwari, M.; Chandra, R. The effect of the aqueous extract of the roots of Asparagus racemosus on hepatocarcinogenesis initiated by diethylnitrosamine. Phytother. Res. 2008, 22, 1175-1182. [CrossRef] [PubMed] 
5. Dahanukar, S.; Thatte, U.; Pai, N.; Mose, P.; Karandikar, S. Protective effect of Asparagus racemosus against induced abdominal sepsis. Research 1986, 24, 125-128.

6. Elena, K. First report of Phomopsis asparagi causing stem blight of asparagus in Greece. Plant Pathol. 2006, 55, 300. [CrossRef]

7. Fuentes-Alventosa, J.; Jaramillo-Carmona, S.; Rodríguez-Gutiérrez, G.; Guillén-Bejarano, R.; Jiménez-Araujo, A.; Fernández-Bolaños, J.; Rodríguez-Arcos, R. Preparation of bioactive extracts from asparagus by-product. FBP 2013, 91, 74-82. [CrossRef]

8. Sahu, R.; Saxen, J. Screening of total phenolic and flavonoid content in conventional and non-conventional species of Curcuma. J. Pharmacogn. Phytochem. 2013, 2, 176-179.

9. Fan, R.; Yuan, F.; Wang, N.; Gao, Y.; Huang, Y. Extraction and analysis of antioxidant compounds from the residues of Asparagus officinalis L. J. Food Sci. Technol. 2015, 52, 2690-2700. [CrossRef] [PubMed]

10. Farasat, M.; Khavari-Nejad, R.-A.; Nabavi, S.M.B.; Namjooyan, F. Antioxidant activity, total phenolics and flavonoid contents of some edible green seaweeds from northern coasts of the Persian Gulf. Iran. J. Pharm. Res. 2014, 13, 163-170. [PubMed]

11. Herald, T.J.; Gadgil, P.; Tilley, M. High-throughput microplate assays for screening flavonoid content and DPPH-scavenging activity in sorghum bran and flour. J. Sci. Food Agric. 2012, 92, 2326-2331. [CrossRef] [PubMed]

12. De-Ancos, B.; Sgroppo, S.; Plaza, L.; Cano, M.P. Possible nutritional and health-related value promotion in orange juice preserved by high-pressure treatment. J. Sci. Food Agric. 2002, 82, 790-796. [CrossRef]

13. Huang, D.; Ou, B.; Hampsch-Woodill, M.; Flanagan, J.A.; Prior, R.L. High-throughput assay of oxygen radical absorbance capacity (ORAC) using a multichannel liquid handling system coupled with a microplate fluorescence reader in 96-well format. J. Agric. Food Chem. 2002, 50, 4437-4444. [CrossRef] [PubMed]

14. Benzie, I.F.; Strain, J. The ferric reducing ability of plasma (frap) as a measure of "antioxidant power": The frap assay. Anal. Biochem. 1996, 239, 70-76. [CrossRef] [PubMed]

15. Teh, S.S.; Niven, B.E.; Bekhit, A.E.D.A.; Carne, A.; Birch, E.J. The use of microwave and pulsed electric field as a pretreatment step in ultrasonic extraction of polyphenols from defatted hemp seed cake (Cannabis sativa) using response surface methodology. Food Bioprocess Technol. 2014, 7, 3064-3076. [CrossRef]

16. Złotek, U.; Mikulska, S.; Nagajek, M.; Świeca, M. The effect of different solvents and number of extraction steps on the polyphenol content and antioxidant capacity of basil leaves (Ocimum basilicum L.) extracts. Saudi J. Biol. Sci. 2016, 23, 628-633.

17. Carter, W.P.; Pierce, J.A.; Luo, D.; Malkina, I.L. Environmental chamber study of maximum incremental reactivities of volatile organic compounds. Atmos. Environ. 1995, 29, 2499-2511. [CrossRef]

18. McMartin, K.E.; Ambre, J.J.; Tephly, T.R. Methanol poisoning in human subjects: Role for formic acid accumulation in the metabolic acidosis. Am. J. Med. 1980, 68, 414-418. [CrossRef]

19. Perini, M.; Camin, F. $\Delta 18$ o of ethanol in wine and spirits for authentication purposes. J. Food Sci. 2013, 78, C839-C844. [CrossRef] [PubMed]

20. Boussetta, N.; Lesaint, O.; Vorobiev, E. A study of mechanisms involved during the extraction of polyphenols from grape seeds by pulsed electrical discharges. Innov. Food Sci. Emerg. Technol. 2013, 19, 124-132. [CrossRef]

21. Guillén, R.; Rodríguez, R.; Jaramillo, S.; Rodríguez, G.; Espejo, J.A.; Fernández-Bolaños, J.; Heredia, A.; Jiménez, A. Antioxidants from asparagus spears: Phenolics. Acta Hortic. 2008, 776, 247-253. [CrossRef]

22. Lee, E.J.; Yoo, K.S.; Patil, B.S. Development of a rapid HPLC-UV method for simultaneous quantification of protodioscin and rutin in white and green asparagus spears. J. Food Sci. 2010, 75, C703-C709. [CrossRef] [PubMed]

23. Lee, J.H.; Lim, H.J.; Lee, C.W.; Son, K.H.; Son, J.K.; Lee, S.K.; Kim, H.P. Methyl protodioscin from the roots of Asparagus cochinchinensis attenuates airway inflammation by inhibiting cytokine production. Evid.-Based Complement. Altern. Med. 2015, 2015, 640846. [CrossRef] [PubMed]

24. Solana, M.; Boschiero, I.; Dall'Acqua, S.; Bertucco, A. A comparison between supercritical fluid and pressurized liquid extraction methods for obtaining phenolic compounds from Asparagus officinalis L. J. Supercrit. Fluids 2015, 100, 201-208. [CrossRef]

25. Shi, J.; Yu, J.; Pohorly, J.; Young, J.C.; Bryan, M.; Wu, Y. Optimization of the extraction of polyphenols from grape seed meal by aqueous ethanol solution. J. Food Agric. Environ. 2003, 1, 42. 
26. Bekhit, A.E.-D.A.; Cheng, V.J.; Harrison, R.; Ye, Z.; Bekhit, A.A.; Ng, T.; Kong, L. Technological aspects of by-product utilization. In Valorization of Wine Making By-Products; Chapter 4; CRC Press: Boca Raton, FL, USA, 2016; p. 117.

27. Nawaz, H.; Shi, J.; Mittal, G.S.; Kakuda, Y. Extraction of polyphenols from grape seeds and concentration by ultrafiltration. Sep. Purif. Technol. 2006, 48, 176-181. [CrossRef]

28. Renard, C.M.; Baron, A.; Guyot, S.; Drilleau, J.-F. Interactions between apple cell walls and native apple polyphenols: Quantification and some consequences. Int. J. Biol. Macromol. 2001, 29, 115-125. [CrossRef]

29. Cacace, J.; Mazza, G. Mass transfer process during extraction of phenolic compounds from milled berries. J. Food Eng. 2003, 59, 379-389. [CrossRef]

30. Bazykina, N.; Nikolaevskii, A.; Filippenko, T.; Kaloerova, V. Optimization of conditions for the extraction of natural antioxidants from raw plant materials. Pharm. Chem. J. 2002, 36, 46-49. [CrossRef]

31. Diankov, S.; Karsheva, M.; Hinkov, I. Extraction of natural antioxidants from lemon peels. Kinetics and antioxidant capacity. J. Chem. Technol. Met. 2011, 46, 315-319.

32. Payne, A.C.; Mazzer, A.; Clarkson, G.J.J.; Taylor, G. Antioxidant assays-Consistent findings from FRAP and ORAC reveal a negative impact of organic cultivation on antioxidant potential in spinach but not watercress or rocket leaves. Food Sci. Nutr. 2013, 1, 439-444. [CrossRef] [PubMed]

33. Miller, H.G.; Ikawa, M.; Peirce, L.C. Caffeic acid identified as an inhibitory compound in asparagus root filtrate. HortScience 1991, 26, 1525-1527.

34. Huang, X.F.; Luo, J.; Zhang, Y.; Kong, L.Y. Chemical constituents of Asparagus officinalis. Chin. J. Nat. Med. 2006, 4, 181-184.

35. Lake, R.; Falloon, P.; Cook, D. Replant problem and chemical components of asparagus roots. N. Z. J. Crop Hortic. Sci. 1993, 21, 53-58. [CrossRef]

36. Makris, D.P.; Rossiter, J.T. Domestic processing of onion bulbs (Allium cepa) and asparagus spears (Asparagus officinalis): Effect on flavonol content and antioxidant status. J. Agric. Food Chem. 2001, 49, 3216-3222. [CrossRef] [PubMed]

37. Son, S.; Lewis, B.A. Free radical scavenging and antioxidative activity of caffeic acid amide and ester analogues: Structure-Activity relationship. J. Agric. Food Chem. 2002, 50, 468-472. [CrossRef] [PubMed]

38. Fu, W.; Wang, H.; Ren, X.; Yu, H.; Lei, Y.; Chen, Q. Neuroprotective effect of three caffeic acid derivatives via ameliorate oxidative stress and enhance pka/creb signaling pathway. Behav. Brain Res. 2017, 328, 81-86. [CrossRef] [PubMed]

(C) 2018 by the authors. Licensee MDPI, Basel, Switzerland. This article is an open access article distributed under the terms and conditions of the Creative Commons Attribution (CC BY) license (http:/ / creativecommons.org/licenses/by/4.0/). 